\title{
Autophagy induced by purple pitanga (Eugenia uniflora L.) extract triggered a cooperative effect on inducing the hepatic stellate cell death
}

\author{
Cristiane C. Denardin - Leo A. M. Martins - Mariana M. Parisi • \\ Moema Queiroz Vieira • Silvia R. Terra • Florencia M. Barbé-Tuana • \\ Radovan Borojevic • Márcia Vizzotto • Tatiana Emanuelli • \\ Fátima Costa Rodrigues Guma
}

Received: 14 May 2016/Accepted: 7 October 2016

(C) Springer Science+Business Media Dordrecht 2016

\begin{abstract}
Activated hepatic stellate cells (HSC) are the major source of collagen I in liver fibrosis. Eugenia uniflora L. is a tree species that is widely distributed in South America. E. uniflora L. fruit-popularly known as pitang $a$ - has been shown to exert beneficial properties. Autophagy contributes to the maintenance of cellular homeostasis and survival under stress situation, but it has also been suggested to be an alternative cell death pathway. Mitochondria play a pivotal role on signaling cell death. Mitophagy of damaged mitochondria is an important cell defense mechanism against organellemediated cell death signaling. We previously found that purple pitanga extract induced mitochondrial dysfunction, cell cycle arrest, and death by apoptosis and
\end{abstract}

$\underline{\text { Cristiane C. Denardin and Leo A. M. Martins contributed equally. }}$

C. C. Denardin · L. A. M. Martins · M. M. Parisi •

M. Q. Vieira · S. R. Terra · F. M. Barbé-Tuana •

F. C. R. Guma

Programa de Pós-Graduação em Ciências Biológicas-Bioquímica, ICBS, Universidade Federal do Rio Grande do Sul, Porto Alegre, RS, Brasil

C. C. Denardin

Curso de Farmácia, Universidade Federal do Pampa

(UNIPAMPA), Campus Uruguaiana, Uruguaiana, RS, Brasil

F. C. R. Guma $(\bowtie)$

Departamento de Bioquímica, Universidade Federal do Rio Grande do Sul, Rua Ramiro Barcelos 2600-Anexo, Lab 21, CEP: 90035-003 Porto Alegre, RS, Brasil

e-mail: fatima.guma@ufrgs.br necrosis in GRX cells, a well-established activated HSC line. We evaluated the effects of 72-h treatment with crescent concentrations of purple pitanga extract (5 to $100 \mu \mathrm{g} / \mathrm{mL}$ ) on triggering autophagy in GRX cells, as this is an important mechanism to cells under cytotoxic conditions. We found that all treated cells presented an increase in the mRNA expression of autophagy-related protein 7 (ATG7). Concomitantly, flow cytometry and ultrastructural analysis of treated cells revealed an increase of autophagosomes/autolysosomes that consequentially led to an increased mitophagy. As purple pitanga extract was previously found to be broadly cytotoxic to GRX cells, we postulated that autophagy contributes to this scenario, where cell death seems to be

\footnotetext{
T. Emanuelli

Núcleo Integrado de Desenvolvimento em Análises Laboratoriais (NIDAL), Departamento de Tecnologia e Ciência de Alimentos, Universidade Federal de Santa Maria, Santa Maria, RS, Brasil

M. Vizzotto

Empresa Brasileira de Pesquisa Agropecuária de Clima Temperado, Pelotas, RS, Brasil

R. Borojevic

Departamento de Histologia e Embriologia, ICB, UFRJ, Rio de Janeiro, RJ, Brasil

F. C. R. Guma

Centro de Microscopia e Microanálise, Universidade Federal do Rio Grande do Sul, Porto Alegre, RS, Brasil
} 
an inevitable fate. Altogether, the effectiveness on inducing activated HSC death can make purple pitanga extract a good candidate on treating liver fibrosis.

Keywords Autophagy - Cell death - Eugenia uniflora L. fruits $\cdot$ Hepatic stellate cells $\cdot$ Liver fibrosis

\section{Introduction}

Liver fibrosis is the essential pathophysiologic consequence of chronic hepatic injury, representing a common underlying mechanism for hepatic insufficiency and for most clinical complications of end-stage hepatic diseases. This fibrotic process results from the accumulation of extracellular matrix proteins secreted by hepatic stellate cells (HSC) (Friedman 2006, 2008).

HSC are liver-specific pericytes involved in the development of pathological fibrosis. HSC activation, from a quiescent-like state to a myofibroblast-like phenotype, is characterized by many important cellular changes that include loss of vitamin A, acquisition of stress bundles, and striking increase in production and secretion of extracellular matrix proteins - such as types I, III, and IV collagens, fibronectin, laminin, proteoglycans, and among others. Activation is also associated with high expression of smooth muscle $\alpha$ actin, high cell proliferation, and release of pro-inflammatory cytokines (Friedman 2006, 2008). Though it is increasingly clear that other mesenchymal cell populations may also contribute to the extracellular matrix accumulation seen during liver fibrosis, HSC activation remains among the most significant event, traditionally regarded as an irreversible process (Atzori et al. 2009). Experimental studies have shown that different interventions are capable of inhibiting or reversing HSC activation. In addition, the balance between cell proliferation and cell death is of upmost importance on determining the total HSC population in the liver. In this sense, activated HSC may also be induced to senescence or cell death towards fibrogenesis reduction (Friedman 2008; Rockey 2013).

Eugenia uniflora L., popularly known as Pitangueira in Brazil, is a tree species widely distributed in South America. E. uniflora L. leaves are largely used in popular medicine as infusion for the treatment of fever, rheumatism, stomach diseases, and digestive disorders, as well as hypertension, yellow fever, and gout. Leaf infusion may also be able to reduce weight and blood pressure and can be used as a diuretic (Schmeda-
Hirschmann et al. 1987; Alice et al. 1991). E. uniflora L. fruits-popularly known as pitanga or Brazilian cherry - have different flesh colors ranging from orange to purple. Pitanga fruits have been shown to exert antioxidant activity by inhibiting lipid peroxidation and by removing free radicals (Velazquez et al. 2003; Celli et al. 2011; Bagetti et al. 2011). Indeed, pitanga fruits may have healthy benefits due to their high concentrations of classical antioxidant compounds, such as anthocyanins, flavonoids, and carotenoids. Due to the great Brazilian flora, several plants that may have therapeutic potential have not been fully studied. Likewise, a low number of works have explored the health benefits of E. uniflora L. fruits (Bagetti et al. 2011; Celli et al. 2011; Denardin et al. 2015; Skrovankova et al. 2015).

In general, tissues have a basal level of autophagy, an evolutionarily conserved process that leads to the degradation of organelles and proteins, contributing to the maintenance of cellular homeostasis against environment stress. In this condition, autophagy allows cells to degrade damaged organelles, such as non-functional mitochondria, thus facilitating cell surviving (Eisenberg-Lerner and Kimchi 2007; Booth et al. 2014). On the other hand, it has also been suggested that autophagy is an alternative way leading to cell death when apoptosis is impossible (Fuchs and Steller 2015). We previously found that purple pitanga extract was able to reduce the viability of GRX cells (Denardin et al. 2014), a well-established activated HSC line (Borojevic et al. 1985; Vicente et al. 1998; Geerts 2001; De Souza et al. 2015), and this result seems to be very promisor towards liver fibrosis regression. Here, we evaluated the effects of purple pitanga extract on promoting autophagy in GRX because this cellular mechanism is very important to cells under cytotoxic conditions. In addition, this elucidation may be helpful on determining how effective purple pitanga extract can be in reducing activated HSC population.

\section{Materials and methods}

\section{Reagents}

Fluorescent dry Acridine Orange (AO) was purchased from Sigma-Aldrich Chemical Co. (St. Louis, MO, USA). qPCR kit GoTaq ${ }^{\circledR}$ Master Mix was purchased from Promega (Fitchburg, WI, USA). TRIzol reagent, Superscript First-Strand Synthesis System kit, 
MitoTracker Green FM (MTG), Lysotracker Red DND99 (LYSR), and all culture reagents were purchased from Invitrogen (Carlsbad, CA, USA). All reagents were analytical grade.

Preparation of fruit extracts

Samples of purple-fleshed breeding line of pitanga fruits (E. uniflora L.) were obtained from harvest at Embrapa Temperate Climate (Pelotas, RS, Brazil) and immediately frozen. Samples were prepared searching for a mixture of completely ripe fruits from various plant selections with purple flesh. Three independent samples were collected, frozen at $-18{ }^{\circ} \mathrm{C}$, and transported to the Federal University of Santa Maria (Santa Maria, RS, Brazil). Extract of purple pitanga was prepared from the edible portions of fruits. Briefly, fresh fruit samples were homogenized with an ultra-turrax homogenizer for $5 \mathrm{~min}$ in $95 \%$ ethanol (1:3, $w / v$ ). The homogenates were blended for $30 \mathrm{~min}$ at room temperature and centrifuged at $1500 \times \mathrm{g}$ for $5 \mathrm{~min}$. The supernatant was collected and the extraction procedure was repeated. The pooled supernatants were concentrated in rotary evaporator at $40{ }^{\circ} \mathrm{C}$. The samples were reconstituted in water and stored at $-80^{\circ} \mathrm{C}$. Total phenolic content was measured according to the Folin-Ciocalteu method adapted from Swain \& Hillis (Swain and Hillis 1959). The absorbance was measured at $725 \mathrm{~nm}$ and the results were expressed as chlorogenic acid equivalents (CAE; $\mu \mathrm{g} / \mathrm{mL})$ using a chlorogenic acid $(0-0.4 \mathrm{mg} / \mathrm{mL})$ standard curve. The stock concentration of purple pitanga extract was $20.725 \mathrm{mg} \mathrm{CAE} / \mathrm{mL}$.

\section{Cell culture and treatments}

The GRX cell line was obtained from the livers of $\mathrm{C} 3 \mathrm{H} /$ $\mathrm{HeN}$ mice that were infected by transcutaneous penetration of cercarias from the Schistosoma mansoni $\mathrm{BH}$ strain (Borojevic et al. 1985) and was kindly provided by the Cell Bank of Rio de Janeiro (Federal University of Rio de Janeiro, RJ, Brazil). Cell treatment and all experimental procedures were performed at Federal University of Rio Grande do Sul (Porto Alegre, RS, Brazil). Cells were routinely maintained in Dulbecco's modified minimum essential medium (DMEM) supplemented with $5 \%$ fetal bovine serum (FBS) and $2 \mathrm{~g} / \mathrm{L}$ HEPES buffer (pH 7.4). Cells were plated $\left(5 \times 10^{4} / \mathrm{mL}\right)$ in 12- or 24-well plates and cultured under $37^{\circ} \mathrm{C}$ and $5 \% \mathrm{CO}_{2}$ conditions for $24 \mathrm{~h}$ to reach $60-70 \%$ of confluence before treatment. Purple pitanga extract was diluted in culture medium to final concentrations of 5, 50, and $100 \mu \mathrm{g} / \mathrm{mL}$ just before use. The GRX cells were treated in the dark for $72 \mathrm{~h}$.

Quantification of autophagy-related protein 7 (ATG7) mRNA expression by RT-PCR

The total RNA from GRX cells was extracted using TRIzol reagent according to the manufacturer's protocol. After extraction, total RNA was quantified by UV absorbance in a spectrobiophotometer (BioPhotometer Plus, Eppendorf, Hamburg, Germany). RNA integrity was analyzed on $1 \%$ formamide-agarose gel. Reverse transcription of the mRNA into cDNA was performed with $3 \mu \mathrm{g}$ of total RNA, using the Superscript First-Strand Synthesis System kit according to manufacturer's instructions. The synthesized cDNA was used for quantitative real time polymerase chain reaction (RT-qPCR). The RT-qPCR was performed in triplicate with the qPCR GoTaq ${ }^{\circledR}$ Master Mix kit in a thermocycler (StepOnePlus ${ }^{\mathrm{TM}}$, Applied Biosystems, CA, USA). Primers were designed using the design software IDT (Integrated DNA Technologies Inc., USA), according to the gene sequences available at GenBank (www.ncbi.nlm.nih.gov) and Ensembl (www.ensembl.org). The sequences of ATG7 primers (NCBI accession number: NM_001253717) were as follows: forward: 5' AGC CTG TTC ACC CAA AGT TC 3' and reverse: 5' CGT CAC TCATGT CCC AGATC $3^{\prime}$. The sequences of B2M primers (NCBI accession number: NM_009735.3), used for normalization, were as follows: forward 5'-TCC TGG CTC ACA CTG AAT TC$3^{\prime}$ and reverse 5'-CTG CGT GCA TAA ATT GTA TAG CA-3'. Reaction settings were composed of an initial denaturation step of $5 \mathrm{~min}$ at $94{ }^{\circ} \mathrm{C}$, followed by 40 cycles of $10 \mathrm{~s}$ at $94{ }^{\circ} \mathrm{C}, 15 \mathrm{~s}$ at $60{ }^{\circ} \mathrm{C}, 15 \mathrm{~s}$ at $72{ }^{\circ} \mathrm{C}$, and $35 \mathrm{~s}$ at $60^{\circ} \mathrm{C}$ for data acquisition. Samples were kept for $2 \mathrm{~min}$ at $40^{\circ} \mathrm{C}$ for annealing and then heated from 55 to $99^{\circ} \mathrm{C}$ at a rate of $0.1^{\circ} \mathrm{C} / \mathrm{s}$ to produce the denaturing curve of the amplified products. The specificity of amplification and absence of primer dimers were confirmed using melting curve analysis at the end of each run. All results were analyzed by the $2^{-\Delta \Delta \mathrm{CT}}$ method (Livak and Schmittgen 2001).

Quantification of autophagosome by Acridine Orange (AO) staining

For autophagosome quantification, cells were harvested by trypsinization and then analyzed by flow cytometry 
(FACScan Calibur, BD Bioscience). When internalized, $\mathrm{AO}$ emits green fluorescence in the whole cell except in acidic vacuolar organelles (AVO), where it fluoresces red. Development of AVO is a typical feature of autophagy because only mature/late autophagosomes are acidic (Klionsky et al. 2008). Briefly, GRX cells were incubated with $\mathrm{AO}(2.7 \mu \mathrm{M})$ for $15 \mathrm{~min}$ at room temperature. Ten thousand events were acquired for each sample to measure green (FL-1 channel) and red (FL-3 channel) fluorescence, by which stained mature autophagosomes were quantified. All data analyses were performed with FCS Express 4 software (De novo, Ontario, Canada).

Ultrastructural analysis by transmission electron microscopy

Semi-confluent control and treated GRX cells were collected by trypsinization. Cells were harvested by centrifugation and washed twice. After, cells were fixed in a mixture of $4 \%$ paraformaldehyde and $2.5 \%$ glutaraldehyde buffered with $0.1 \mathrm{M}$ phosphate $(\mathrm{pH} 7.3)$ at room temperature, and then post-fixed in osmium tetroxide in the same buffer for $45 \mathrm{~min}$. Dehydration was done in a graded acetone series (30-100\%) and embedding in araldite (Durcupan ACM, Fluka) for $72 \mathrm{~h}$ at $60{ }^{\circ} \mathrm{C}$. Thin sections $(70 \mathrm{~nm})$ were stained with $2 \%$ uranyl acetate followed by lead citrate. Ultrastructural analysis was performed on randomly selected 50 fields of each group in a JEM 1200EX II transmission electron microscopy.

Mitophagy evaluation through laser-scanning confocal microscopy

Confocal experiments were performed to evaluate the incidence of mitophagy. Cells were co-incubated in the dark for $20 \mathrm{~min}$ in prewarmed $\left(37^{\circ} \mathrm{C}\right)$ DMEM containing $100 \mathrm{nM}$ of MitoTracker Green FM (MTG), a fluorescent probe for mitochondrial staining, and $75 \mathrm{nM}$ of Lysotracker Red DND-99 (LYSR), a fluorescent probe for lysosomal staining. Experiments were repeated at least three times for each sample and images were collected using a Laser-scanning confocal microscopy (Olympus FV 1000, Tokyo, Japan). Ten single confocal sections of $0.7 \mu \mathrm{m}$ were taken parallel to the cover slip (xy sections) using the UPLSAPO $60 \times$ waterimmersion objective lens. The Intensity Correlation Analysis plugin of imageJ software (http://rsb.info.nih. gov/ij/) was used to perform colocalization analysis and
Pearson correlation coefficient calculi in four regions of interest (measuring $95 \mu^{2}$ each one) that were overlaid on the acquired images (measuring $200 \mu \mathrm{m}^{2}$ each one).

\section{Statistical analysis}

Data were reported as mean \pm standard deviations (SD). Results were analyzed by one-way analysis of variance (ANOVA) followed by Tukey's test $(p<0.05)$. All analyses and graphical were performed using the statistical software GraphPad Prism 5 for Windows (GraphPad Software Inc., version 5.01).

\section{Results and discussion}

Activation of HSC from a quiescence state to a myofibroblast-like state is the central event leading to liver fibrogenesis. GRX line is a well-established model of activated HSC that can be tested for studying strategies that may be favorable towards liver fibrosis regression (Borojevic et al. 1990; Geerts 2001; Borojevic et al. 1985). Recent studies have revealed the important role of autophagy - a catabolic mechanism involving cell degradation of unnecessary or dysfunctional cellular components through the lysosomal pathway-on the HSC phenotypical transition during liver fibrosis development. Indeed, an increased autophagy flux that contributes to the intracellular catabolism of lipid droplets and mitochondrial oxidation in quiescent HSC is necessary to provide the essential energy that supports the cell phenotypic transition to activation. It was already shown that inhibition of autophagy (through deleting any of the autophagy-related genes or using autophagy inhibitors) reduced the activation of HSC in vitro and after liver injury, which led to reduced fibrosis (Ni et al. 2012; Rautou et al. 2010; Rockey 2013; Thoen et al. 2011).

A large number of autophagy-related proteins (ATG) are known to be hierarchically recruited towards the autophagosome formation. The microtubule-associated protein 1A/1B-light chain 3 (LC3) is a protein that exists in a soluble form named LC3-I and converts to the autophagy vesicle-associated form named LC3-II, an important step on autophagosome maturation. Among ATGs, ATG7 is known to be an important signaling molecule involved in the LC3-I conversion to LC3-II (Codogno et al. 2012). Thus, we firstly sought to evaluate whether ATG7 gene expression (mRNA) was altered by treatment with purple pitanga extract. We 
found that all concentrations $(5,50$, and $100 \mu \mathrm{g} / \mathrm{mL})$ significantly increased the expression of ATG7 after $72 \mathrm{~h}$ of treatment in a similar way (Fig. 1a). Through flow cytometry of AO stained cells, we found that GRX treated with 50 and $100 \mu \mathrm{g} / \mathrm{mL}$ of purple pitanga extract presented a significant increase in the number of mature

Control $\square 5 \mu \mathrm{g} / \mathrm{mL} \square 50 \mu \mathrm{g} / \mathrm{mL} \square 100 \mu \mathrm{g} / \mathrm{mL}$

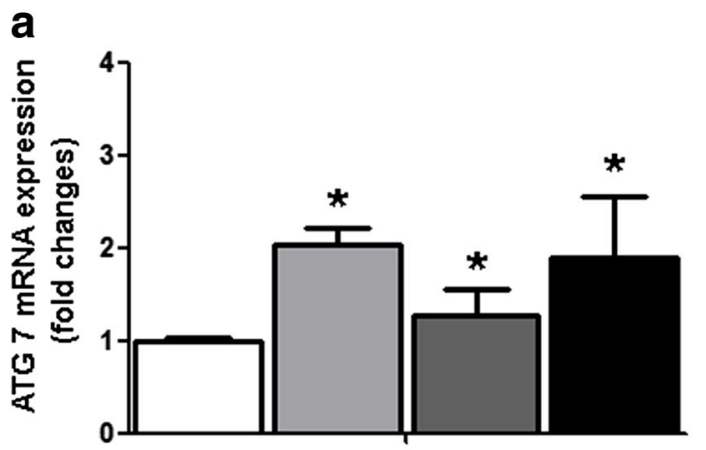

b
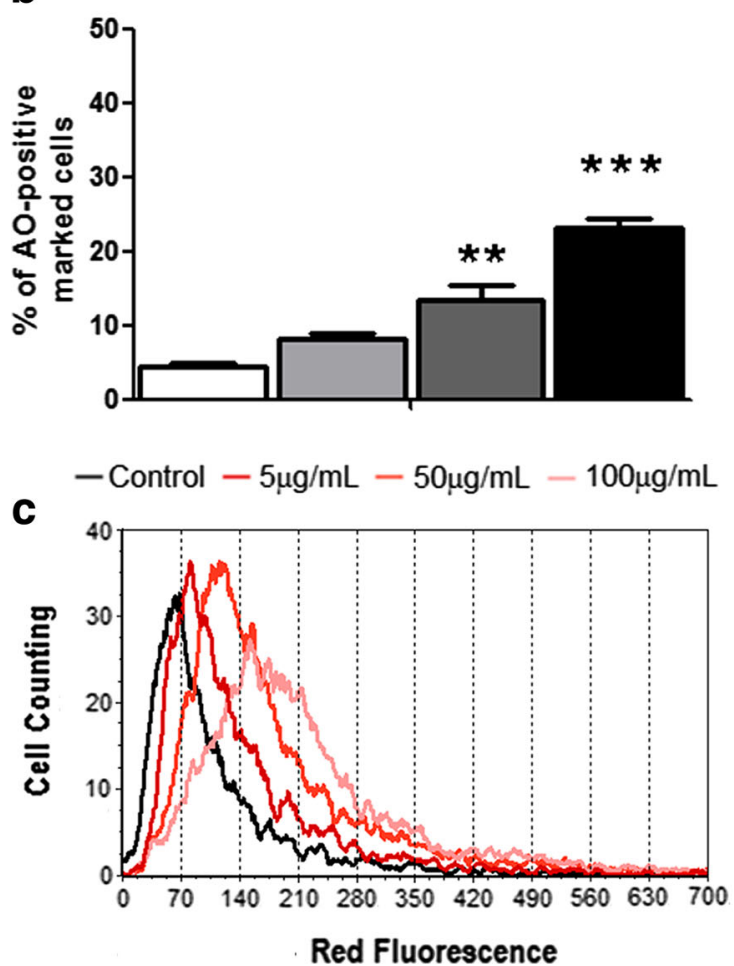

Fig. 1 Purple pitanga extract increased autophagy in GRX. Cells were treated with 5,50 , and $100 \mu \mathrm{g} / \mathrm{mL}$ of purple pitanga extract for $72 \mathrm{~h}$. a Expression of ATG7 by RT-qPCR. b Percentage of cells with positive red fluorescence, indicating that GRX treated with 50 and $100 \mu \mathrm{g} / \mathrm{mL}$ of purple pitanga extract presented an increase of mature autophagosomes. c Representative histogram of flow cytometry results. Values are shown as mean \pm SD. ${ }^{*} p<0.05$, $* * p<0.01$, and $* * * p<0.001$ vs. untreated (control) cells autophagosome that seemed to be dose dependent (Fig. 1b, c). Ultrastructural analysis revealed an evident increase in the number of autophagosomes and autolysosomes in cells treated with 5 and $100 \mu \mathrm{g} / \mathrm{mL}$ of purple pitanga extract (Fig. 2). It is worthwhile to observe that although there was a similar increase in ATG7 expression (mRNA), the ATG7 protein translation may also be important for the autophagic pathway and could be related to the dose-dependent effect on the autophagosome maturation. Altogether, our results reveal that even the lower concentration of purple pitanga extract can be sufficient to trigger the signaling required for increasing autophagosome maturation.

Mitochondria play a pivotal role in cell metabolism and cell survival. Main pathways of cell death are activated in response to mitochondrial dysfunction. Moderate injuries lead to an increase of pores in the mitochondrial outer membrane that results in cytochrome $c$ release into the cell's cytosol, marking a defined event associated to apoptosis. However, in a radical stress situation, a prominent increase of mitochondrial permeability can culminate in cell necrosis (Kroemer et al. 2007). Originally, it was believed that autophagy was a strictly non-selective process, randomly engulfing cytosolic components. Later, the concept of "targeted" or "specific" autophagy, in which autophagosomes were observed to preferentially degrade particular macromolecular constituents within the cytosol, has been the subject of intense debate (Goldman et al. 2010; Klionsky et al. 2008). In this way, the presence of mitochondria within autophagosomes and lysosomes is a type of autophagy that has been called mitophagy, a cellular mechanism that plays an important role on removing and degrading impaired organelles that could trigger cell death, contributing to cell survival (Goldman et al. 2010; Kim et al. 2007). Confocal imaging analysis of MTG and LYSR co-labeled cells revealed the mitochondrial translocation into lysosomes in cells treated with 50 and $100 \mu \mathrm{g} / \mathrm{mL}$ of purple pitanga extract (Fig. 3a). The calculi of Pearson correlation coefficient revealed that mitophagy increased in a dose-dependent way (Fig. 3b, c).

We have already shown the potential of purple pitanga extract on GRX cell viability. Treatment for $72 \mathrm{~h}$ with crescent concentrations that ranged from 5 to $100 \mu \mathrm{g} / \mathrm{mL}$ was able to trigger cell cycle arrest and cell death by apoptosis and necrosis (Denardin et al. 2014). Recently, our group demonstrated that resveratrol, a polyphenol present in red wine and grape skin, 
Fig. 2 Accumulation of autophagosomes and autolysosomes in GRX treated with purple pitanga extract. Representative images of transmission electron microscopic showing cell cytoplasm regions. GRX cells were cultured in standard DMEM containing $5 \%$ FBS (control cells) (a, b), and treated with $5 \mu \mathrm{g} / \mathrm{mL}(\mathbf{c}, \mathbf{d})$ or $100 \mu \mathrm{g} / \mathrm{mL}(\mathbf{e}, \mathbf{f})$ of purple pitanga extract. $A$

autophagosomes, $A L$ autolysosomes, $E R$ endoplasmic reticulum, $M$ mitochondria, $N$ nucleus
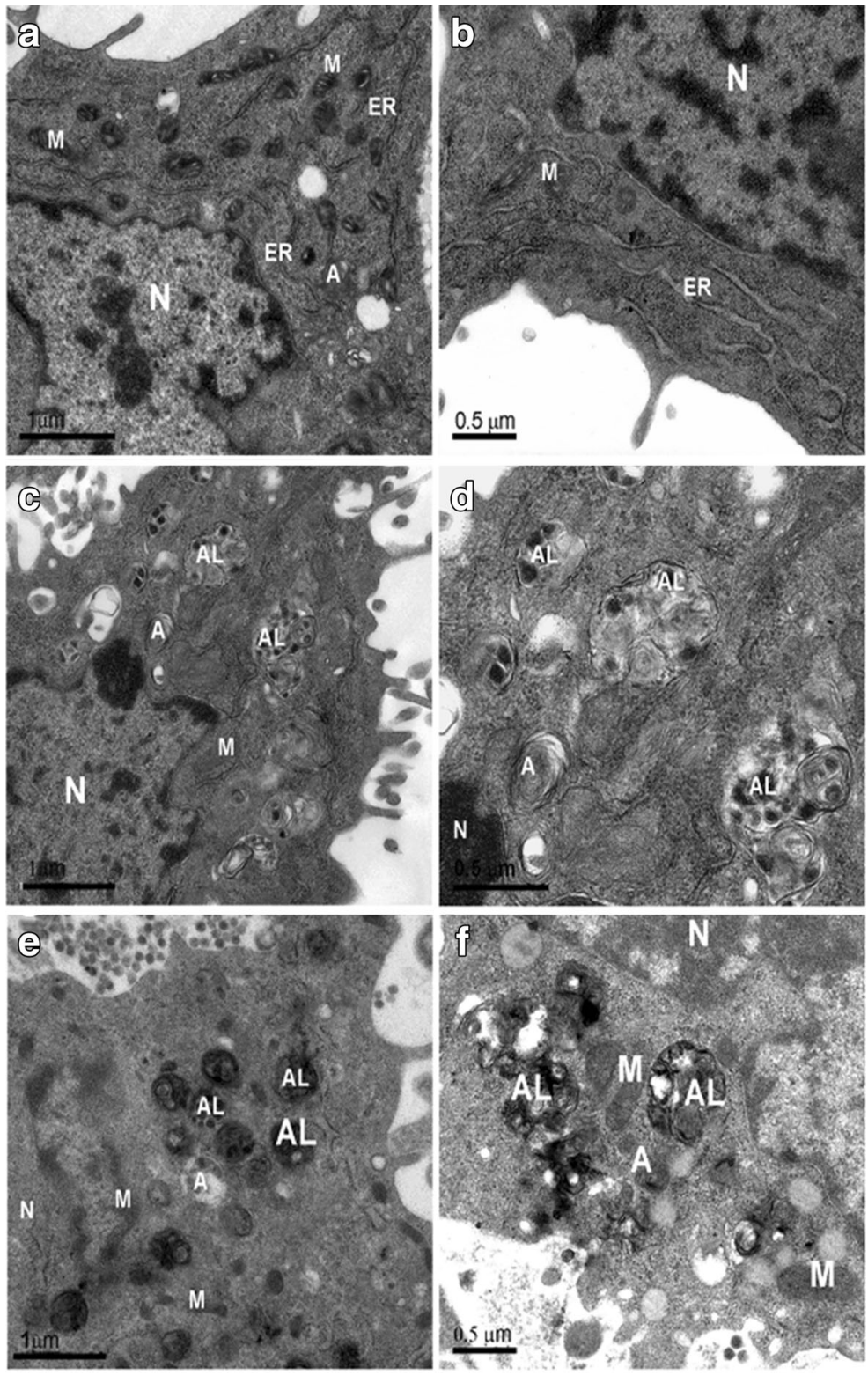

was cytotoxic to GRX cells through promoting oxidative stress and mitochondrial disruption that led to cell injury. However, resveratrol-related cytotoxicity was attenuated by the concomitant induction of mitochondrial biogenesis and autophagy of dysfunctional organelles (mitophagy). The interplay between these events seemed to be crucial on determining the GRX fate for death or survival (Martins et al. 2014a, b). Here, in our new settings, we also observed a similar effect when purple pitanga extract was added to GRX cultured cells, inducing autophagy and mitophagy (Fig. 3a). This result
Fig. 3 Mitochondrial translocation into acidic organelles during purple pitanga extract treatment. GRX cells were co-incubated with MTG and LYSR as mentioned in the "Materials and methods" section. a Representative images $\left(95 \mu \mathrm{m}^{2}\right)$ of mitochondria-lysosomes complex through superimposition of mitochondria (green fluorescence) and lisosome (red fluorescence). Colocalization mask represents mitophagy. b Colocalization quantification according to Pearson coefficient calculi (mean obtained from three independent experiments). c Representative dot plot for green-red fluorescence: spread dots indicate low colocalization whereas grouped dots indicate higher colocalization. Values are shown as mean $\pm \mathrm{SD}$. $* * * p<0.001$ vs. untreated (control) cells 

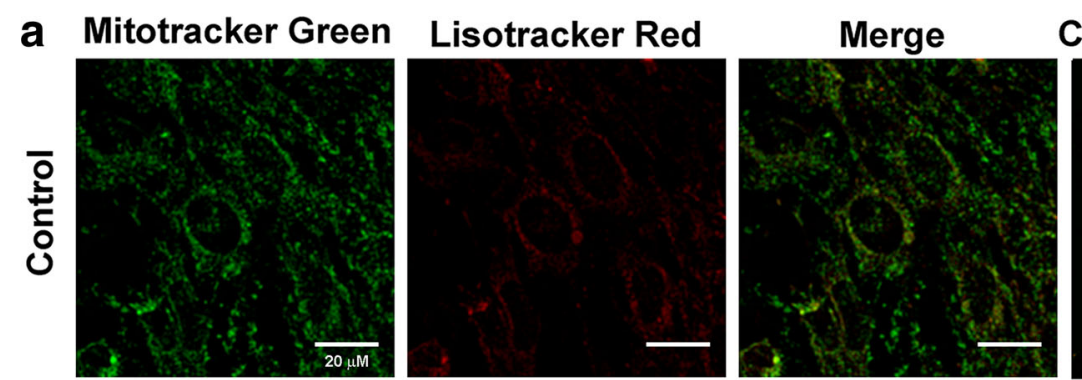

Colocalization Mask
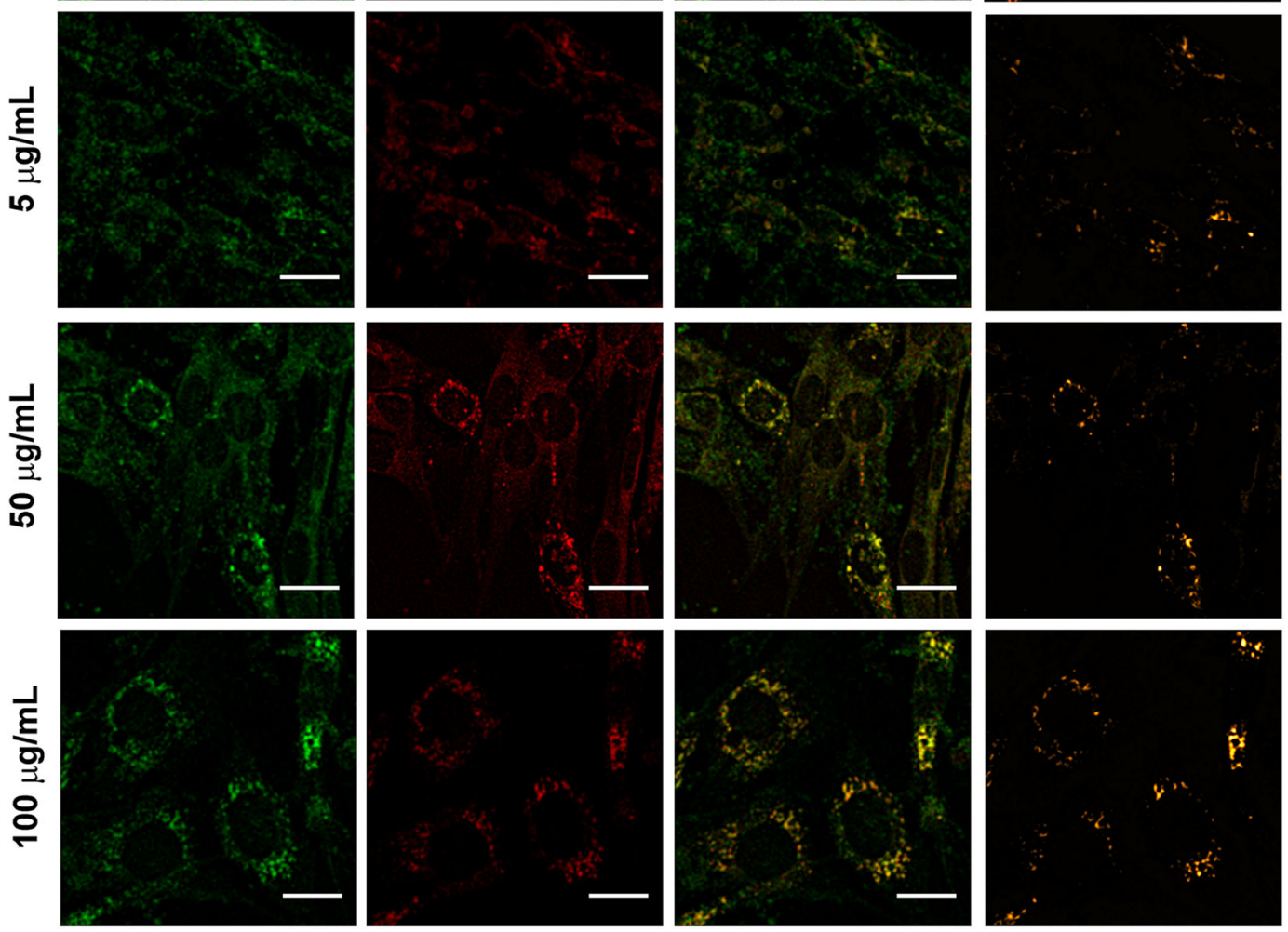

b

$\square$ Control $\square 5 \mu \mathrm{g} / \mathrm{mL} \square 50 \mu \mathrm{g} / \mathrm{mL} \square 100 \mu \mathrm{g} / \mathrm{mL}$
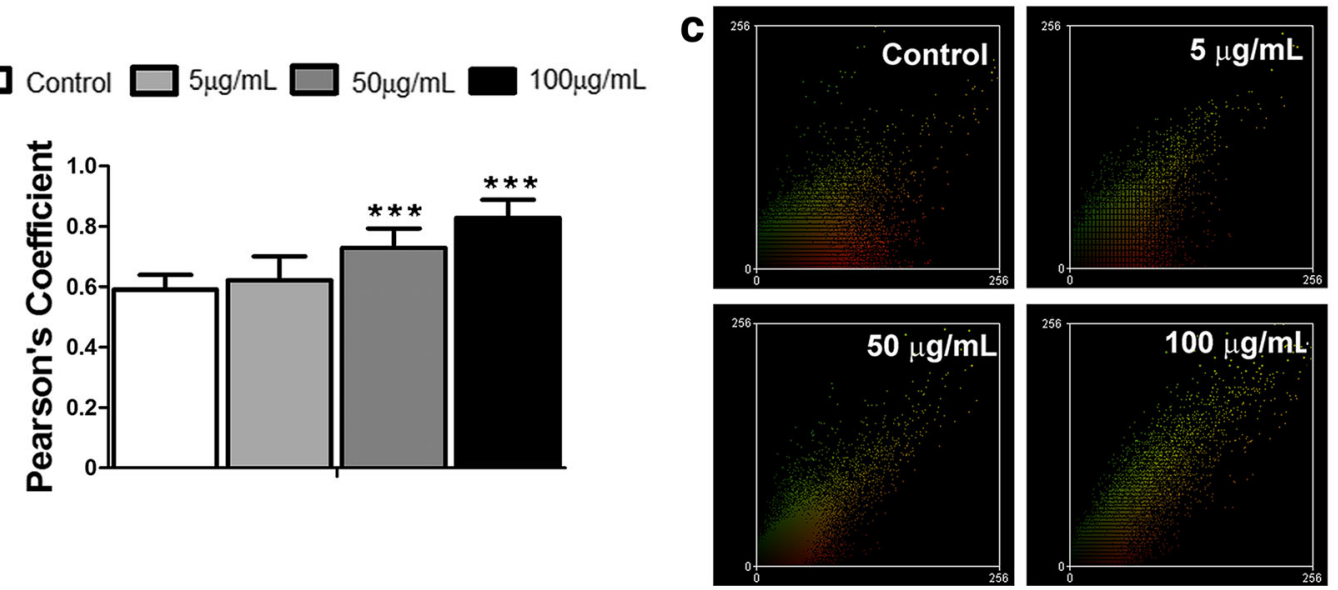
also suggests a plausible cell defense against nonfavorable cellular environmental conditions. However, it is worthwhile to emphasize that treatment with purple pitanga extract not only damaged mitochondrial function but also drastically reduced the mitochondrial content in GRX (Denardin et al. 2014), which suggests that there was no organelle improvement or replacement.

Many studies have shown the antiproliferative and cytotoxic effects of natural compounds-including resveratrol, catechin, quercetin, and others - in activated HSC, which may contribute to reducing liver fibrogenesis (Kawada et al. 1998; Souza et al. 2008; Braganca De Moraesn et al. 2012). Contrary to its protective effect, autophagy has also been suggested to lead or contribute to cell death in certain scenarios. In fact, the autophagic cell death (historically known as type II cell death) perhaps gave the false impression that autophagic machinery is responsible for cell death. However, the presence of a large number of autophagosomes usually accompanied cell death, thus raising the question of whether autophagy is an unsuccessful attempt at survival rather than a cell death mechanism. Indeed, the relationship between cell death mechanisms and autophagy is quite complex and critical for cellular viability (Fuchs and Steller 2015; EisenbergLerner and Kimchi 2007). Altogether, the autophagy/ mitophagy induction by purple pitanga extract did not seem to contribute to the cell defense against its exacerbated cytotoxicity. Contrariwise, cell death appears to be an inevitable fate and autophagy appears to cooperate with this event. Thus, the autophagic removal of damaged cellular structures, including mitochondria, with no replacement for healthy organelles may actually contribute to cell death (Fig. 4).

Autophagy plays an important role in the activation of HSC (Thoen et al. 2011). However, here, this mechanism appeared to act in synergism on inducing the GRX cell death, thus contributing to the great cytotoxic effect of purple pitanga extract. From these results, more studies should be conducted to better understand

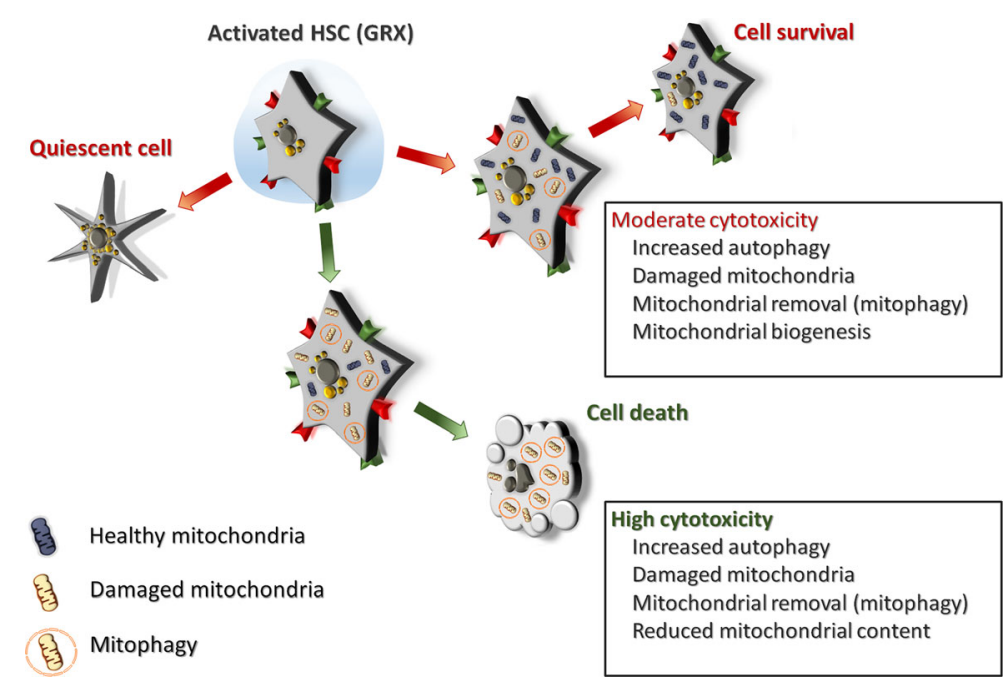

Fig. 4 Purple pitanga extract and liver fibrosis regression. The reduction of activated HSC population remains among the most important strategy for liver fibrosis regression. The reversion of activated HSC to their quiescent state contributes to the decrease of fibrogenesis, although a decrease of cell population in this case not necessarily occurs (red arrow to left). Focusing on cell proliferation and/or viability, there is an effective possibility for achieving activated HSC population decrease. Natural compounds have been studied for this purpose (Friedman 2006, 2008). Autophagy contributes to the maintenance of cellular homeostasis against the environment stress, thus facilitating cell surviving (Codogno et al. 2012). Contrary to its protective effect, autophagy has also been suggested to lead or contribute to cell death in certain scenarios (Fuchs and Steller 2015). In this way, we previously showed that resveratrol was able to decrease proliferation, to

damage mitochondria, and to induce cell death signaling. However, the concomitant induction of autophagy/mitophagy and mitochondrial biogenesis seemed to attenuate the resveratrol-related cytotoxicity; thus, surviving cells remained viable and proliferative (red arrow to right) (Souza et al. 2008; Martins et al. 2014a, b). Purple pitanga extract was also able to induce cell cycle arrest and cell death, which was accompanied by a great mitochondrial disruption and loss of function (Denardin et al. 2014). Here, we found that purple pitanga extract triggered autophagy and mitophagy, but this mechanism was not able to attenuate its previously described cytotoxicity; contrariwise, cell death was an inevitable fate. Furthermore, autophagic removal of damaged cellular structures with no replacement for healthy organelles may contribute to cell death (green arrow) 
the signaling interaction between cell death events and autophagy induced by the purple pitanga extract in GRX. Although the effectiveness on inducing activated HSC death makes extract of purple pitanga a good candidate on treating liver fibrosis, a range of bioactive nutrients composes pitanga fruits and their bioavailability can differ between them. In addition, since HSC play an important role at the liver as a whole, the response of other hepatic cells to purple pitanga extract must be evaluated. Therefore, in vivo studies must also be conducted to strengthen these results.

Acknowledgments The authors acknowledge Conselho Nacional de Desenvolvimento Cientifico e Tecnológico (CNPq), Coordenação de Aperfeiçoamento de Pessoal de Nivel Superior (CAPES), and Fundação de Amparo à Pesquisa do Rio Grande do Sul (FAPERGS) for financial support; and Embrapa Clima Temperado for their collaboration and supply of fruit samples. The authors thank to Centro de Microscopia e Microanálise (CMM-UFRGS) by technical assistance in confocal and transmission electron microscopy.

\section{References}

Alice CB, Vargas VM, Silva GA, et al. Screening of plants used in south Brazilian folk medicine. J Ethnopharmacol. 1991;35: 165-71.

Atzori L, Poli G, Perra A. Hepatic stellate cell: a star cell in the liver. Int J Biochem Cell Biol. 2009;41:1639-42.

Bagetti M, Facco EMP, Piccolo J, et al. Physicochemical characterization and antioxidant capacity of pitanga fruits (Eugenia uniflora L.). Cienc Tecnol Aliment. 2011;31:147-54.

Booth LA, Tavallai S, Hamed HA, et al. The role of cell signalling in the crosstalk between autophagy and apoptosis. Cell Signal. 2014;26:549-55.

Borojevic R, Monteiro AN, Vinhas SA, et al. Establishment of a continuous cell line from fibrotic schistosomal granulomas in mice livers. In Vitro Cell Dev Biol. 1985;21:382-90.

Borojevic R, Guaragna RM, Margis R, et al. In vitro induction of the fat-storing phenotype in a liver connective tissue cell lineGRX. In Vitro Cell Dev Biol. 1990;26:361-8.

Braganca De Moraesn CM, Melo DA, Santos RC, et al. Antiproliferative effect of catechin in GRX cells. Biochem Cell Biol. 2012;90:575-84.

Celli GB, Pereira-Netto AB, Beta T. Comparative analysis of total phenolic content, antioxidant activity, and flavonoids profile of fruits from two varieties of Brazilian cherry (Eugenia uniflora L.) throughout the fruit developmental stages. Food Res Int. 2011;44:2442-51.

Codogno P, Mehrpour M, Proikas-Cezanne T. Canonical and noncanonical autophagy: variations on a common theme of selfeating? Nat Rev Mol Cell Biol. 2012;13:7-12.

De Souza IC, Martins LA, De Vasconcelos M, et al. Resveratrol regulates the quiescence-like induction of activated stellate cells by modulating the PPARgamma/SIRT1 ratio. J Cell Biochem. 2015;116:2304-12.

Denardin CC, Parisi MM, Martins LA, et al. Antiproliferative and cytotoxic effects of purple pitanga (Eugenia uniflora L.) extract on activated hepatic stellate cells. Cell Biochem Funct. 2014;32:16-23.

Denardin CC, Hirsch GE, Da Rocha RF, et al. Antioxidant capacity and bioactive compounds of four Brazilian native fruits. $\mathrm{J}$ Food Drug Anal. 2015;23:387-98.

Eisenberg-Lerner A, Kimchi A. DAP-kinase regulates JNK signaling by binding and activating protein kinase $\mathrm{D}$ under oxidative stress. Cell Death Differ. 2007;14:1908-15.

Friedman SL. Transcriptional regulation of stellate cell activation. J Gastroenterol Hepatol. 2006;21(Suppl 3):S79-83.

Friedman SL. Hepatic stellate cells: protean, multifunctional, and enigmatic cells of the liver. Physiol Rev. 2008;88:125-72.

Fuchs Y, Steller H. Live to die another way: modes of programmed cell death and the signals emanating from dying cells. Nat Rev Mol Cell Biol. 2015;16:329-44.

Geerts A. History, heterogeneity, developmental biology, and functions of quiescent hepatic stellate cells. Semin Liver Dis. 2001;21:311-35.

Goldman SJ, Taylor R, Zhang Y, et al. Autophagy and the degradation of mitochondria. Mitochondrion. 2010;10:309-15.

Kawada N, Seki S, Inoue M, et al. Effect of antioxidants, resveratrol, quercetin, and $\mathrm{N}$-acetylcysteine, on the functions of cultured rat hepatic stellate cells and Kupffer cells. Hepatology. 1998;27:1265-74.

Kim I, Rodriguez-Enriquez S, Lemasters J. Selective degradation of mitochondria by mitophagy. Arch Biochem Biophys. 2007;462:245-53.

Klionsky DJ, Abeliovich H, Agostinis P, et al. Guidelines for the use and interpretation of assays for monitoring autophagy in higher eukaryotes. Autophagy. 2008;4:151-75.

Kroemer G, Galluzzi L, Brenner C. Mitochondrial membrane permeabilization in cell death. Physiol Rev. 2007;87:99-163.

Livak KJ, Schmittgen TD. Analysis of relative gene expression data using real-time quantitative PCR and the 2(-Delta Delta C(T)) method. Methods. 2001;25:402-8.

Martins LA, Coelho BP, Behr G, et al. Resveratrol induces prooxidant effects and time-dependent resistance to cytotoxicity in activated hepatic stellate cells. Cell Biochem Biophys. 2014a;68:247-57.

Martins LA, Vieira MQ, Ilha M, et al. The interplay between apoptosis, mitophagy and mitochondrial biogenesis induced by resveratrol can determine activated hepatic stellate cells death or survival. Cell Biochem Biophys. 2014b;71:657-72.

Ni HM, Williams JA, Yang H, et al. Targeting autophagy for the treatment of liver diseases. Pharmacol Res. 2012;66:463-74.

Rautou P-E, Mansouri A, Lebrec D, et al. Autophagy in liver diseases. J Hepatol. 2010;53:1123-34.

Rockey DC. Translating an understanding of the pathogenesis of hepatic fibrosis to novel therapies. Clin Gastroenterol Hepatol. 2013;11:224-231.e5.

Schmeda-Hirschmann G, Theoduloz C, Franco L, et al. Preliminary pharmacological studies on Eugenia uniflora leaves: xanthine oxidase inhibitory activity. J Ethnopharmacol. 1987;21:183-6.

Skrovankova S, Sumczynski D, Mlcek J, et al. Bioactive compounds and antioxidant activity in different types of berries. Int J Mol Sci. 2015;16:24673-706. 
Souza IC, Martins LA, Coelho BP, et al. Resveratrol inhibits cell growth by inducing cell cycle arrest in activated hepatic stellate cells. Mol Cell Biochem. 2008;315:1-7.

Swain T, Hillis WE. The phenolic constituents of Prunus domestica. I. - the quantitative analysis of phenolic constituents. J Sci Food Agric. 1959;10:63-8.

Thoen LF, Guimaraes EL, Dolle L, et al. A role for autophagy during hepatic stellate cell activation. J Hepatol. 2011;55: 1353-60.
Velazquez E, Tournier HA, Mordujovich De Buschiazzo P, et al. Antioxidant activity of Paraguayan plant extracts. Fitoterapia. 2003;74:91-7.

Vicente CP, Fortuna VA, Margis R, et al. Retinol uptake and metabolism, and cellular retinol binding protein expression in an in vitro model of hepatic stellate cells. Mol Cell Biochem. 1998;187:11-21. 